\title{
GERMINAÇÃO, AVALIAÇÃO DO ÁCIDO GIBERÉLICO E POSIÇÃO DO EXPLANTE NO ALONGAMENTO IN VITRO DE Uncaria guianensis (AUBLET) GMELIN RUBIACEAE (UNHA-DE-GATO) ${ }^{1}$
}

\author{
Germination, avaliation of giberelic acid and position of explants in vitro \\ of Uncaria guianensis (Aublet) Gmelin Rubiaceae (cat's claw )
}

\author{
Rita de Cassia Alves Pereira ${ }^{2}$, José Eduardo Brasil Pereira Pinto ${ }^{3}$, Suzan Kely Vilela Bertolucci ${ }^{3}$, \\ Evaristo Mauro de Castro ${ }^{4}$, Fabiano Guimarães Silva ${ }^{5}$
}

\begin{abstract}
RESUMO
$\mathrm{Na}$ Amazônia existe uma diversidade vegetal, onde se encontram muitas plantas com propriedades medicinais e, que durante milênios são utilizadas pelas comunidades nativas. Uma dessas plantas é a unha-de-gato (Uncaria guianensis), cujo valor medicinal se atribui a efeitos imuno-estimulantes, anti-inflamatório e inibidores de crescimento de células cancerígenas. Atualmente, a espécie vem sendo submetida a uma extração indiscriminada e intensiva, podendo levá-la a sua extinção. A micropropagação permite solucionar problemas dessa natureza. Objetivou-se com este trabalho identificar um protocolo de propagação in vitro desta espécie. O melhor meio para germinação dos embriões foi $1 / 4$ de MS independente da presença ou não de sacarose. A posição de inoculação do explante da espécie Uncaria guianensis demonstrou exercer influência no número médio de brotações/explante original, assim como no número de gemas iniciais. Presença ou ausência de ácido giberélico não exerceu efeito nesta característica, exceto quando explantes com uma única gema foram inoculados na horizontal.
\end{abstract}

Termos para indexação: Micropropagação, planta medicinal, embriões, unha-de-gato.

\begin{abstract}
In the Amazon Rain Forest there are a great botanical diversity where can be found a lot of plants with medicinal proprieties, and for ages it has been used by the native people. One of those plants is Uncaria guianensis known as Cat's Claw to which is believed to have antinflammatories, immunostimulating and growth inhibitors effects on cancerigenic cells. Nowadays, those species have been under uncontrolled and long extraction that could take to extinction. The micropropagation can solve these problems. The purpose of this work was to identify in vitro propagation protocol from these specie. The best medium for embryo germination was $1 / 4$ MS independent from presence or absence of saccarose. The explant inoculation position from Uncaria guianensis specie influenciated the shoots average number/original explant, as well as, the initial buds numbers. The giberelic acid presence or absence had not effect on this characteristics, except when explants with only one bud were inoculated in the horizontal position.
\end{abstract}

Index terms: Micropropagation, medicinal plant, embryos, Cat's Claw.

(Recebido para publicação em 26 de janeiro de 2005 e aprovado em 27 de junho de 2005)

\section{INTRODUÇÃO}

Uncaria guianensis, conhecida popularmente como unha-de-gato, é uma trepadeira lenhosa de ocorrência na Amazônia peruana, parte da Amazônia brasileira e também no Mato Grosso. O nome popular está associado aos espinhos encontrados na base de cada par de folhas. Essa planta tem sido usada tradicionalmente pelos indígenas peruanos e brasileiros há centenas de anos e os rumores de suas curas milagrosas despertaram, nos últimos trinta anos, o interesse científico e comercial (SILVA et al., 2002).

O interesse medicinal é decorrente da indicação popular como imuno-estimulante e anti-inflamatório. Atualmente, a espécie vem sendo submetida à extração indiscriminada e intensiva, o que poderá levá-la à diminuição da variabilidade genética ou até mesmo a sua extinção (CAROTENUDO, 1997).

A propagação da unha de gato pode ser feita por sementes, que em geral apresenta boa germinação. No entanto, plantas advindas de sementes apresentam grande variabilidade quanto à morfologia e ao teor de metabólitos. O problema principal da unha de gato, é a diversidade genética dentro da espécie por ser muito variada, devido a cruzamentos ou por ecótipos ligados à distribuição geográfica, gerando heterogeneidade das características químicas desejadas (TORREJÓN, 1997).

Para a micropropagação em plantas duas estratégias têm sido utilizadas: a regeneração de calos e a multiplicação

${ }^{1}$ Parte da Tese apresentada à Universidade Federal de Lavras/UFLA - Cx. P. 3037 - 37200-000 - Lavras/MG, pelo primeiro autor.

2Pesquisadora da Embrapa Agroindústria Tropical - R. Dra. Sara Mesquita - Cx.P.3761 - 60511-110 - Fortaleza/CE - cassia@cnpat.embrapa.br

${ }^{3}$ Professor do Departamento de Agricultura, Universidade Federal de Lavras/UFLA - Cx. P. 3037 - $37200-000$ - Lavras/MG.

${ }^{4}$ Professor do Departamento de Biologia, Universidade Federal de Lavras/UFLA - Cx. P. 3037 - 37200-000 - Lavras/MG.

${ }^{5}$ Professor do CEFET - Laboratório de Cultura de Tecidos - Cx. P. 66 - Rio Verde, GO - fabiano@cefetrv.edu.br 
de brotos. A regeneração de calos resulta em alta porcentagem de variação somaclonal, sendo questionável para a multiplicação clonal em larga escala. Por outro lado, a multiplicação de broto, é um método que pode ser utilizado na propagação clonal de diversas espécies (EINSET, 1986).

A regeneração de plantas in vitro tem obtido sucesso a partir de gemas apicais e axilares e explantes nodais para várias espécies da família Morácea (HOSSAIN et al., 1992; MHATRE et al., 1985; PATTNAIK et al., 1996).

As auxinas e as citocininas são as classes de reguladores de crescimento mais utilizadas na cultura de tecidos. A formação de raiz, parte aérea e calo em cultura de tecidos são regulados pela disponibilidade e interação dessas duas classes de reguladores de crescimento (SKOOG \& MILLER, 1957). O efeito desses reguladores pode está relacionado com os fatores genéticos próprios de cada espécie (MORALES, 1990).

As giberelinas têm como principal efeito estimular o crescimento de órgãos já formados, mas podem inibir a iniciação de outros processos de formação de órgãos (GEORGE \& SHERRINGTON, 1984; MURASHIGE, 1974). As giberelinas incrementam tanto a divisão celular quanto o alongamento das células formadas (TAIZ \& ZEIGER, 1991).

Objetivou-se com este trabalho estudar a propagação in vitro de unha-de-gato por meio de germinação in vitro de embriões e avaliar o efeito do ácido giberélico $\left(\mathrm{GA}_{3}\right)$ e segmentos nodais pela adição de ácido giberélico ao meio de cultivo MS.

\section{MATERIAL E MÉTODOS}

As sementes utilizadas de unha-de-gato (Uncaria guianensis) são provenientes da Embrapa Acre (AC), coletadas de plantas adultas de populações naturais do município de Boca do Acre-AM.

Os experimentos foram conduzidos no Laboratório de Cultura de Tecidos e Plantas Medicinais do Departamento de Agricultura da Universidade Federal de Lavras (UFLA).

Para análise estatística de todos os experimentos utilizou-se o programa Sisvar (FERREIRA, 2002).

\section{Germinação in vitro}

Inicialmente as sementes foram lavadas em água corrente por 10 minutos e posteriormente desinfestadas em câmara de fluxo laminar, com solução de hipoclorito de sódio $(1,25 \%)$ durante 15 minutos. Após a desinfestação, as sementes foram lavadas quatro vezes com água destilada e autoclavada para remoção do excesso da solução desinfestante.

Os embriões foram excisados e inoculados em tubos de ensaio de $25 \times 150 \mathrm{~mm}$, contendo $10 \mathrm{~mL}$ de meio de cultura
Murashige \& Skoog (1962), em duas concentrações: MS completo e $1 / 4$ de MS, solidificado com 6,0 g.L. $\mathrm{L}^{-1}$ de ágar em combinação com 0,0 e 15 g.L. $\mathrm{L}^{-1}$ de sacarose. $\mathrm{O}$ pH do meio foi ajustado em 5,7 antes da autoclavagem. Após a inoculação, os embriões foram mantidos em sala de crescimento com fotoperíodo de 16 horas, nível de irradiância de $15 \mathrm{mmol} \cdot \mathrm{m}^{-2} \cdot \mathrm{s}^{-1}$, e temperatura de $25^{\circ} \mathrm{C}$, durante 34 dias, quando se avaliou a porcentagem de germinação e comprimento das plântulas.

$\mathrm{O}$ delineamento experimental foi o inteiramente casualizado (DIC) com quatro tratamentos e cinco repetições de 4 tubos cada uma constituindo um fatorial $2 \times 2$ sendo duas as concentrações do meio de cultivo (MS completo $1 / 4$ de MS) suplementados $\left(15\right.$ g. $\left.\mathrm{L}^{-1}\right)$ ou não $\left(0,0 \mathrm{~g}\right.$. $\left.\mathrm{L}^{-1}\right)$ com sacarose. Utilizou-se o teste de Tukey ao nível de 5\% para a comparação das médias dos tratamentos.

\section{Avaliação do ácido giberélico e posição do explante no alongamento in vitro de unha-de-gato}

Segmentos nodais de plântulas estabelecidas in vitro oriundos com 1, 2 e 3 gemas, foram inoculados em meio de cultura MS (MURASHIGE \& SKOOG, 1962) na concentração padrão dos sais, vitaminas e inositol e $30 \mathrm{~g} . \mathrm{L}^{-1}$ de sacarose, acrescido de $6 \mathrm{~g} . \mathrm{L}^{-1}$ de ágar, $\mathrm{pH}$ ajustado para 5,7 $\pm 0,1$ antes da autoclavagem.

Os tratamentos consistiram na combinação de duas posições de inoculação (horizontal e vertical) presença ou ausência de $\mathrm{GA}_{3}\left(0\right.$ ou $0,5 \mathrm{~g}$. $\left.\mathrm{L}^{-1}\right)$ com 1,2 e 3 . Os tubos foram mantidos em sala de crescimento, com fotoperíodo de 16 horas, intensidade luminosa de $15 \mathrm{mmol} \cdot \mathrm{m}^{-2} . \mathrm{s}^{-1}$, e temperatura de $25^{\circ} \mathrm{C}$.

$\mathrm{O}$ experimento foi disposto em delineamento inteiramente casualizado em esquema fatorial $(2 \times 2 \times 3)$, totalizando 12 tratamentos com três repetições ( 8 tubos/ repetição). Após 45 dias, foram avaliados número e comprimento das brotações, fitomassa fresca e seca das plântulas e presença de raízes.

\section{RESULTADOS E DISCUSSÃO}

\section{Germinação in vitro de unha-de-gato}

As sementes de Uncaria guianensis apresentaram porcentagem média de germinação de $90 \%$ uma semana após a inoculação dos embriões. Não houve efeito significativo da adição de sacarose e concentração do meio de cultura na germinação dos embriões de unha-de-gato. Percentuais de germinação de $100 \%$ ocorreram na presença de 15 g.L. $\mathrm{L}^{-1}$ de sacarose, independente da concentração do meio de cultivo MS. O meio contendo $1 / 4$ de MS na presença de sacarose proporcionou maior comprimento da parte aérea das plântulas (Tabela 1). 
Estes resultados encontram suporte semelhante aos relatados por Pinheiro et al. (2001), que verificaram que as maiores taxas de germinação em sementes de mangaba (Hancornia speciosa Gomez) foram encontradas quando se utilizaram baixas concentrações de sacarose. Souza (2003), trabalhando com Lychnophora pinaster Mart., obteve melhor porcentagem de embriões germinados e maior comprimento da parte aérea em meio contendo 1/4 de MS. Grattapaglia \& Machado (1998) afirmam que em alguns casos para espécies lenhosas, o meio MS em $100 \%$ de sua concentração não mostrou melhores resultados. George (1996) admite que as soluções de sais orgânicos e açúcares que compõem os meios de cultura de tecidos não possuem efeito puramente nutritivo, mas influenciam o crescimento celular e a morfogênese por meio de propriedades osmóticas.

Na Figura 1 mostra-se o efeito das diferentes concentrações do meio MS na ausência e presença de sacarose na germinação de embriões de Uncaria guianensis.

Avaliação do ácido giberélico e posição do explante no alongamento in vitro de unha-de-gato

A posição de inoculação do explante demonstrou exercer influência no número médio de brotações alongadas/ explante original, assim como o número de gemas iniciais. Presença ou ausência de $\mathrm{GA}_{3}$ não exerceu efeito nesta característica, exceto quando explantes com uma única gema foram inoculados na horizontal, proporcionando números reduzidos de brotações finais, comparado aos explantes inoculados na vertical, independente do número de gemas iniciais ou $\mathrm{GA}_{3}$ (Tabela 2).

Explantes inoculados na horizontal em meios com $\mathrm{GA}_{3}$ respondem ao acréscimo de gemas iniciais, aumentando o número de brotações finais, fato não observado quando estes foram inoculados em ausência de GA Yui et al. (1990), trabalhando com macieira cv. "Golden Delicious", observaram que não houve diferença significativa para os níveis de 0,$0 ; 0,01 ; 0,1$ e $1,0 \mathrm{mg} \mathrm{L}^{-1}$ de $\mathrm{GA}_{3}$ Os mesmos autores concluíram que o $\mathrm{GA}_{3}$ é dispensável nos trabalhos de multiplicação da macieira in vitro, estando de acordo com as informações de MeloFarias et al. (1998) e Ochatt \& Caso (1983); George (1996) afirma que o efeito do $\mathrm{GA}_{3}$ na proliferação de brotações varia conforme a interação existente com outros reguladores de crescimento, dependendo da espécie que está sendo micropropagada.

Maior comprimento de plantulas originais foi observado em explantes inoculados na horizontal, independente da suplementação com $\mathrm{GA}_{3}$ e do número de gemas iniciais. Explantes inoculados na vertical com uma gema inicial e na presença de $\mathrm{GA}_{3}$ apresentaram comprimento comparável aos melhores tratamentos, ou seja, aos inoculados na horizontal (Tabela 3).

TABELA 1 - Porcentagem de germinação de embriões e comprimento de brotações de Uncaria guianensis inoculados em diferentes concentrações de meio MS na ausência e presença de sacarose. UFLA, Lavras-MG, 2004.

\begin{tabular}{ccc}
\hline Tratamentos & Germinação $(\%)$ & Comprimento de brotações (cm) \\
\hline A & $92,50 \mathrm{a}$ & $0,5 \mathrm{~b}$ \\
B & $92,50 \mathrm{a}$ & $0,6 \mathrm{~b}$ \\
C & $100,00 \mathrm{a}$ & $0,5 \mathrm{~b}$ \\
D & $100,00 \mathrm{a}$ & $1,2 \mathrm{a}$ \\
\hline
\end{tabular}

Médias seguidas pela mesma letra na posição vertical, não diferem entre si pelo teste de Tukey ao nível de $5 \%$ de probabilidade. $(\mathrm{A}=\mathrm{MS} ; \mathrm{B}=1 / 4 \mathrm{MS} ; \mathrm{C}=\mathrm{MS}+$ sacarose; $\mathrm{D}=1 / 4 \mathrm{MS}+$ sacarose $)$.
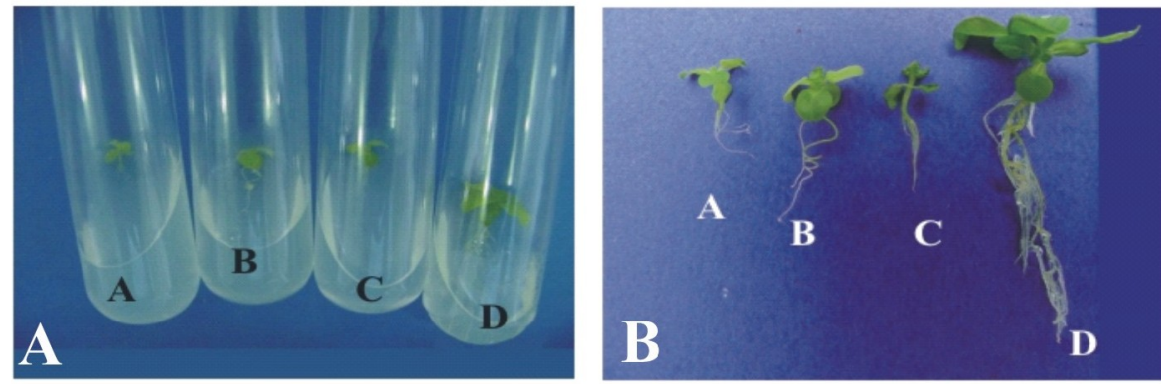

FIGURA 1 - (A) Plântulas obtidas in vitro a partir de sementes de Uncaria guianensis e (B) após 34 dias de inoculação em meio MS com diferentes concentrações na ausência e presença de sacarose. $(\mathrm{A}=\mathrm{MS} ; \mathrm{B}=1 / 4 \mathrm{MS} ; \mathrm{C}=\mathrm{MS}+\mathrm{sacarose}$; $\mathrm{D}=1 / 4 \mathrm{MS}+$ sacarose) . 
TABELA 2 - Número médio de brotações em segmentos nodais de unha-de-gato com diferentes números de gemas (G), inoculados em posições horizontal e vertical em meio MS suplementado ou não com de GA A $_{3}$ UFLA, Lavras-MG, 2004.

\begin{tabular}{llccc}
\hline & Posição de & \multicolumn{3}{c}{ Número de brotos } \\
\cline { 3 - 5 } & inoculação & $\mathbf{1 G}$ & $\mathbf{2 G}$ & $\mathbf{3 G}$ \\
\hline \multirow{2}{*}{ Presença de $\mathrm{GA}_{3}(+)$} & Horizontal & $1,25 \mathrm{Bb}$ & $1,83 \mathrm{Aa}$ & $2,25 \mathrm{Aa}$ \\
& Vertical & $1,08 \mathrm{Bb}$ & $1,08 \mathrm{Bb}$ & $1,20 \mathrm{Bb}$ \\
\hline \multirow{2}{*}{ Ausência de $\mathrm{GA}_{3}(-)$} & Horizontal & $2,17 \mathrm{Aa}$ & $2,00 \mathrm{Aa}$ & $2,08 \mathrm{Aa}$ \\
& Vertical & $1,00 \mathrm{Bb}$ & $1,17 \mathrm{Bb}$ & $1,17 \mathrm{BA}$ \\
\hline
\end{tabular}

Médias seguidas na linha pela mesma letra maiúscula (tipo de explante) e minúscula na coluna (posição de explante ) não diferem entre si pelo Teste de Tukey ao nível de 5\% de probabilidade.

TABELA 3 - Comprimento médio de brotações em explantes foliares de unha-de-gato com diferentes números de gemas (G), inoculados em posições horizontal e vertical em meio MS suplementado ou não com GA 3 UFLA, Lavras-MG, 2004.

\begin{tabular}{lllcc}
\hline & Posição de & \multicolumn{3}{c}{ Comprimento das brotações (cm) } \\
\cline { 3 - 5 } & inoculação & $\mathbf{1 G}$ & $\mathbf{2 G}$ & $\mathbf{3 G}$ \\
\hline \multirow{2}{*}{ Presença de $\mathrm{GA}_{3}(+)$} & Horizontal & $2,25 \mathrm{Aa}$ & $2,47 \mathrm{Aa}$ & $3,08 \mathrm{Aa}$ \\
& Vertical & $2,33 \mathrm{Aa}$ & $1,34 \mathrm{Bb}$ & $1,24 \mathrm{Bb}$ \\
\multirow{2}{*}{ Ausência de $\mathrm{GA}_{3}(-)$} & Horizontal & $2,81 \mathrm{Aa}$ & $2,64 \mathrm{Aa}$ & $2,67 \mathrm{Aa}$ \\
& Vertical & $1,38 \mathrm{Bb}$ & $1,58 \mathrm{Bb}$ & $1,28 \mathrm{Bb}$ \\
\hline
\end{tabular}

Médias seguidas pela mesma letra maiúscula na mesma linha (tipo de explante), e minúscula na mesma coluna (posição de explante) não diferem entre si pelo Teste de Tukey ao nível de 5\% de probabilidade.

De modo semelhante, Oliveira et al. (2001), trabalhando com (Averrhoa bilimbi L.) em meio de cultura contendo $1,0 \mathrm{mg} . \mathrm{L}^{-1}$ de $\mathrm{GA}_{3}$, verificaram que a presença de giberelina pouco contribuiu para o crescimento dos explantes, significando que as giberelinas não promovem respostas positivas.

Mishra et al. (1999) descreveram o alongamento dos internódios de Emblica officinalis Gaertn., quando utilizaram $1 \mathrm{mg} . \mathrm{L}^{-1}$, enquanto $3 \mathrm{mg}$. $\mathrm{L}^{-1}$ causou desfolhamento de alguns explantes. Deccetti (2000) relatou o efeito prejudicial do $\mathrm{GA}_{3}$ no desenvolvimento de brotações de Annona glabra L., além da ocorrência de necrose apical e abscisão foliar. No entanto, Figueredo et al. (2001) relataram a necessidade do $\mathrm{GA}_{3}$ para o alongamento das brotações de Rollinia mucosa Jacq.

Presença de $\mathrm{GA}_{3}$ no meio de cultura não produziu efeito benéfico ao acúmulo de fitomassa. Na maioria em explantes inoculados na horizontal, o número de gemas iniciais influenciou apenas em presença de $\mathrm{GA}_{3}$, quando explantes com uma única gema revelaram fitomassa inferior. Já, nos explantes inoculados na vertical, verificou-se menor acúmulo de fitomassa em explantes com uma única gema na ausência de $\mathrm{GA}_{3}$ (Tabela 4).

Plântulas com maiores acúmulos de fitomassa foram observadas em: explantes inoculados na horizontal sem $\mathrm{GA}_{3}$ independente do número de gemas com peso entre 30 a $40 \mathrm{mg}$. Resultados semelhantes foram encontrados por Fráguas (2003) em plantas micropropagadas de figueira, quando o maior peso da matéria fresca dos explantes inoculados foi de $43 \mathrm{mg}$, na ausência de giberelina. Quando se utilizou duas e três gemas na ausência de $\mathrm{GA}_{3}$, também ocorreu formação de raízes semelhante aos explantes inoculados na vertical. Kochba et al. (1974) citam que a presença de ácido giberélico no meio de cultura proporciona a iniciação de uma zona radicular existente, mas quando aplicado em concentrações elevadas, impede a formação de raízes. Alto percentual de enraizamento e maior número de raízes em Annona glabra foram observados por Deccetti (2000) na ausência de regulador de crescimento. Brum (2001), trabalhando com enraizamento de brotações de Ficus carica L., também afirma que não é necessário utilizar reguladores de crescimento para o enraizamento. 
TABELA 4 - Média de fitomassa seca de brotações em explantes foliares de unha-de-gato com diferentes números de gemas (G), inoculados em posições horizontal e vertical em meio MS suplementado ou não com GA 3 . UFLA, Lavras-MG, 2004.

\begin{tabular}{lllcc}
\hline & Posição de & \multicolumn{3}{c}{ Fitomassa seca de brotações $(\mathbf{m g})$} \\
& inoculação & $\mathbf{1 G}$ & $\mathbf{2 G}$ & $\mathbf{3 G}$ \\
\hline \multirow{2}{*}{ Presença de $\mathrm{GA}_{3}(+)$} & Horizontal & $22,3 \mathrm{Bb}$ & $34,1 \mathrm{Aa}$ & $33,73 \mathrm{Aa}$ \\
& Vertical & $18,33 \mathrm{Cc}$ & $17,61 \mathrm{Cc}$ & $25,18 \mathrm{Bb}$ \\
\hline \multirow{2}{*}{ Ausência de $\mathrm{GA}_{3}(-)$} & Horizontal & $30,10 \mathrm{Aa}$ & $37,60 \mathrm{Aa}$ & $34,18 \mathrm{Aa}$ \\
& Vertical & $16,58 \mathrm{Cc}$ & $23,46 \mathrm{Bb}$ & $25,48 \mathrm{Bb}$ \\
\hline
\end{tabular}

Médias seguidas pela mesma letra maiúscula na mesma linha (tipo de explante) e minúscula na mesma coluna (posição de explante) não diferem entre si pelo Teste de Tukey ao nível de 5\% de probabilidade.

Desse modo, o comportamento observado no desenvolvimento de Uncaria guianensis cultivada in vitro, sugere que a metodologia apresentada pode ser considerada para estudos do desenvolvimento vegetal. Os resultados demonstram que o uso de segmentos nodais com três brotações e inoculados na horizontal são de relevante importância na fase de multiplicação. Esse comportamento corrobora com as observações de Murashige (1974) com Nicotiana tabacum L. e na Pfaffia tuberosa (Spreng.) Hicken (MARTINS et al., 2000).

\section{CONCLUSÕES}

Embriões de Uncaria guianensis são excelentes fontes de explantes para o estabelecimento de cultura in vitro. Os melhores percentuais de germinação ocorrem na presença de 15 g.L de sacarose, independente da concentração do meio de cultivo MS.

A posição de inoculação do explante demonstrou exercer influência no número médio de brotações/explante original de Uncaria guianensis, assim como o número de gemas iniciais. Explantes inoculados na horizontal em meios com $\mathrm{GA}_{3}$ respondem ao acréscimo de gemas iniciais, aumentando o número de brotações finais.

\section{REFERÊNCIAS BIBLIOGRÁFICAS}

BRUM, G. R. Micropropagação da figueira (Ficus carica L.) 'Roxo de Valinhos". 2001. 41 p. Dissertação (Mestrado em Fitoquímica) - Universidade Federal de Lavras, Lavras, 2001.

CAROTENUDO, D. Uncaria tomentosa (Willd) DC. San Marino: Poliedro, 1997. 35 p. (ZETA. Quaderno, 1).

DECCETTI, S. F. C. Propagação in vitro de Annona glabra L. 2000. 101 p. Dissertação (Mestrado em Fitotecnia) Universidade Federal de Lavras, Lavras, 2000.
EINSET, J. W. A practical guide to woody plant micropropagation. Arnoldia, Jamaica Plain, v. 46, p. 36-44, 1986.

FERREIRA, D. F. SISVAR - Sistemas de análises de variância para dados balanceados: programa de análises estatísticas e planejamento de experimentos. Versão 4.3. Lavras: UFLA, 2002.

FIGUEREDO, S. F. L.; ALBARELLO, N.; VIANA, V. R. C. Micropropagation of Rollinia mucosa (Jacq.) Baill. In Vitro Cellular and Developmental Biology Plant, Wallingford, v. 37, n. 4, p. 471-475, July/Aug. 2001.

FRAGUAS, C. B. Micropropagação e aspecto da anatomia foliar da figueira 'Roxo de Valinhos' em diferentes ambientes. 2003. 110 p. Dissertação (Mestrado em Fitotecnia) - Universidade Federal de Lavras, Lavras, 2003.

GEORGE, E. F.; SHERRINGTON, P. D. Plant propagatation by tissue culture: handbook and directory of commercial Laboratories. Eversley: Exegetics, 1984. 593 p.

GEORGE, E. F. Plant propagatation by tissue culture: part 1: the technology. 2. ed. Edington: Exergetics, 1996. 574 p.

GRATTAPAGLIA, D.; MACHADO, A. M. Micropropagação. In: TORRES, A. C.; CALDAS, L. S.; BUSO, J. A. (Eds.). Cultura de tecidos e transformação genética de plantas. Brasília, DF: Embrapa-SPI/EmbrapaCNPH, 1998. p. 83-260.

HOSSAIN, M.; RAHMAN, S. M.; ZAMAN, A.; JOARDER, O. I.; ISLAM, R. Micropropagation of Morus laevigata Wall from mature trees. Plant Cell Reports, New York, v. 11, n. 10, p. 522-524, Sept. 1992. 
KOCHBA, J.; BUTTON, J.; SPIEGEL-ROY, P.; BORNMAN, C. H.; KOCHABA, M. Stimulation of rooting of citrus embryoids by gibberelic acids and adenine sulphate. Annals of Botany, London, v. 38, n. 157, p. 795-802, 1974.

MARTINS, C. F.; NICOLOSO, F. T.; RUSSOWSKI, D.; FORTUNATO, R. P. Micropropagação de ginseng brasileiro (Pfaffia tuberosa (Spreng) Hicken): II. efeito da posição do segmento nodal na brotação. In: CONGRESSOS NACIONAIS DE BOTANICA, 51., 2000, Brasília. Resumos... Brasília: SBB, 2000.

MELO-FARIAS, P. C.; PETERS, J. A.; NAKASU, B. H. Micropropagação de porta-enxerto de Pereira "Old Home" x Farmingdale". Revista Brasileira de Agrociência, Pelotas, v. 2, n. 2, p. 71-78, 1998.

MHATRE, M.; BAPAT, V. A.; RAO, P. S. Regeneration of plants from the culture of leaves and axillary buds in mulberry (Morus indica L). Plant Cell Reports, New York, v. 4, n. 2, p. 78-80, 1985.

MISHRA, M.; SAXENA, R. P.; PATHAK, R. K.; SRIVASTAVA, A. K. Studies on micropropagation of aonla (Emblica officinalis Gaertn). Progressive Horticulture, Chambattia, v. 31, n. 3/4, p. 116-122, Dec. 1999.

MORALES, G. C. F. Influência do AIB e da presença de folhas no enraizamento de estacas de laranjeira “Valencia" e tangerineiras Montenegrinas". 1990. $125 \mathrm{f}$. Dissertação (Mestrado em Fitotecnia) - Faculdade de Agronomia, Universidade Federal do Rio Grande do Sul, Porto Alegre, 1990.

MURASHIGE, T. Plant propagation through tissue cultures. Annual Review of Plant Physiology, Palo Alto, v. 25, p. 1335-166, 1974.

MURASHIGE, T.; SKOOG, F. A revised medium for rapid growth and bioassays with tabacco tissue cultures. Physiologia Plantarum, Copenhagen, v. 15, n. 3, p. 473497, 1962.

PINHEIRO, C. S. R. et al. Germinação in vitro de mangabeira (Hancornia speciosa Gómez) em diferentes meios de cultura. Revista Brasileira de Fruticultura, Jaboticabal, v. 23, n. 2, p. 413-416, ago. 2001.

OCHATT, S. J.; CASO, O. H. In vitro propagation of peach: II. a medium for in vitro multiplication of 56 peach cultivars. Fruit Varieties Journal, [S.1.], v. 40, n. 2, p. 39-48, 1983.

OLIVEIRA, A. K. D. de; ROCHA, R. H. C.; OLIVEIRA, O. F. de; CÂMARA, F. A. A.; Multiplicação in vitro do Bilimbi utilizando-se diferentes concentrações de reguladores de crescimento. Caatinga, [S.1.], v. 14, n. 1/2, p. 37- 41, 2001.

PATTNAIK, S. K.; SAHOO, Y.; CHAND, P. K. Micropropagation of a fruit tree Morus australis Poir.syn .M. acidosa Griff. Plant Cell Reports, New York, v. 15, n. 11, p. 841-845, Aug. 1996.

SILVA, S. R.; ROSARIO, S. L.; MAZZEI, J. L.; D'AVILA, L. A.; SIANI, A. C.; VALENTE, L. M. M. Estudo comparativo da extração e caracterização do perfil em CLAE dos alcalóides de espécies do gênero Uncaria. In: REUNIÃO ANUAL DA SOCIEDADE BRASILEIRA DE QUÍMICA, 25., 2002. Anais... [S.1.]: SBQ, 2002.

SKOOG, F.; MILLER, C. O. Chemical regulation of growth and organ formation in plant tissues cultured in vitro. Symposium of Society for Experimental Biology, New York, v. 11, p. 118-131, 1957.

SOUZA, A. V. de. Propagação in vitro e aspectos anatômicos de arnica (Lychnophora pinaster) Mart. 2003. 127 p. Dissertação (Mestrado em Fitotecnia) - Universidade Federal de Lavras, Lavras, 2003.

TAIZ, L.; ZEIGER, E. Plant Physiology. Redwood City: The Benjamin Cummings, 1991. 559 p.

TORREJÓN, G. D. Uña de gato y produccion sostenible. Lima: Universidad Nacional Agraria La Molina, 1997. $138 \mathrm{p}$.

YUI, E.; CORREA, D. M.; PASQUAL, M.; PINTO, J. E. B. P. Micropropagação in vitro da macieira (Malus domestica Borkh) cultivar "Golden Delicious". Ciência e Prática, Lavras, v. 14, n. 1, p. 56-61, 1990. 